\title{
Adaptação do método freireano para a alfabetização
} infantil

\author{
Adapting Freire's method for children's literacy
}

\section{Adapter la méthode de Freire pour l'alphabétisation des enfants}

Eliane de Paula ROCHA

Ignácio César de BULHÕES

\section{RESUMO}

O presente artigo propõe-se a explicar como o método utilizado por Paulo Freire na alfabetização de adultos pode ser adaptado de maneira eficaz no processo de alfabetização infantil. A concretização do projeto "Minha escola... Minha vida..." permitiu constatar o quanto essa aplicação é válida, uma vez que contribuiu para expandir a ludicidade e possibilitou uma aprendizagem realmente significativa já nos primeiros anos da vida escolar da criança.

Palavras- chave: alfabetização, método, leitura, Freire.

\section{ABSTRACT}

This-article explains how the method used by Paulo Freire in adult literacy can be adapted effectively in the process of children's literacy. The realization of the project "My school ... My life ... " allowed to establish how this application is applies, since it helped to expand the lucidity and enabled a very significant learning during the first years of the child's school.

Index terms: literacy, method, reading, Freire.

1 Autoria/ Pós-graduada em Educação Inclusiva pela Universidade Castelo Branco e em Práticas de Letramento e Alfabetização pela Universidade Federal de São João del Rei

2 Orientação/ Doutor em Filosofia pela Universidade Federal do Rio de Janeiro 


\section{RÉSUMÉ}

Cet article vise à expliquer comment la méthode utilisée par Paulo Freire dans l'alphabétisation des adultes peut être adapté de manière efficace dans le processus de l'alphabétisation des enfants. L'achèvement du projet «Mon école ... Ma vie ... " a été établi comment cette application est valable, car elle a contribué à élargir le jeu et a permis une apprentissage très importante pendant les premières années de la vie scolaire de l'enfant.

Mots-clés: alphabétisation, la méthode, lectureur, Freire.

\section{Introdução}

A leitura é um exercício que desperta o indivíduo para o pensamento crítico, além de ampliar os caminhos da imaginação, criatividade e linguagem. Trata-se de uma atividade enormemente proveitosa que foi e sempre será muito discutida entre teóricos e estudiosos das mais distintas épocas.

Diante disso, viu-se a necessidade de adaptar o_método desenvolvido por Paulo Freire - educador brasileiro de extraordinária importância para o desenvolvimento da pedagogia crítica em todo o mundo - para o ensino básico. No decorrer da discussão descreveremos como é esse método e como foi feita a adaptação do mesmo.

O objetivo deste artigo é mostrar as relações entre leitura do "mundo" e leitura da "palavra", e o quanto o método freireano é aplicável não só à alfabetização de adultos, mas também de crianças, como comprovou o projeto "Minha escola... Minha vida...". 


\section{Breve histórico sobre Paulo Freire}

No dia 19 de setembro de 1921, em Recife (PE), nascia aquele que viria a ser um dos maiores educadores do Brasil e do mundo: Paulo Reglus Neves Freire, filho de Edeltrudes Neves Freire e Joaquim Temístocles Freire.

O menino Paulo foi alfabetizado pelos próprios pais antes mesmo de chegar à escola. Desde muito novo, conviveu com a miséria e a pobreza do interior nordestino devido aos problemas econômicos enfrentados pela família, especialmente após a morte de seu pai, em 1934. Sem dúvida, o enfrentamento de uma infância difícil foi uma experiência crucial para o desenvolvimento de sua teoria, que trabalha com a própria realidade do indivíduo.

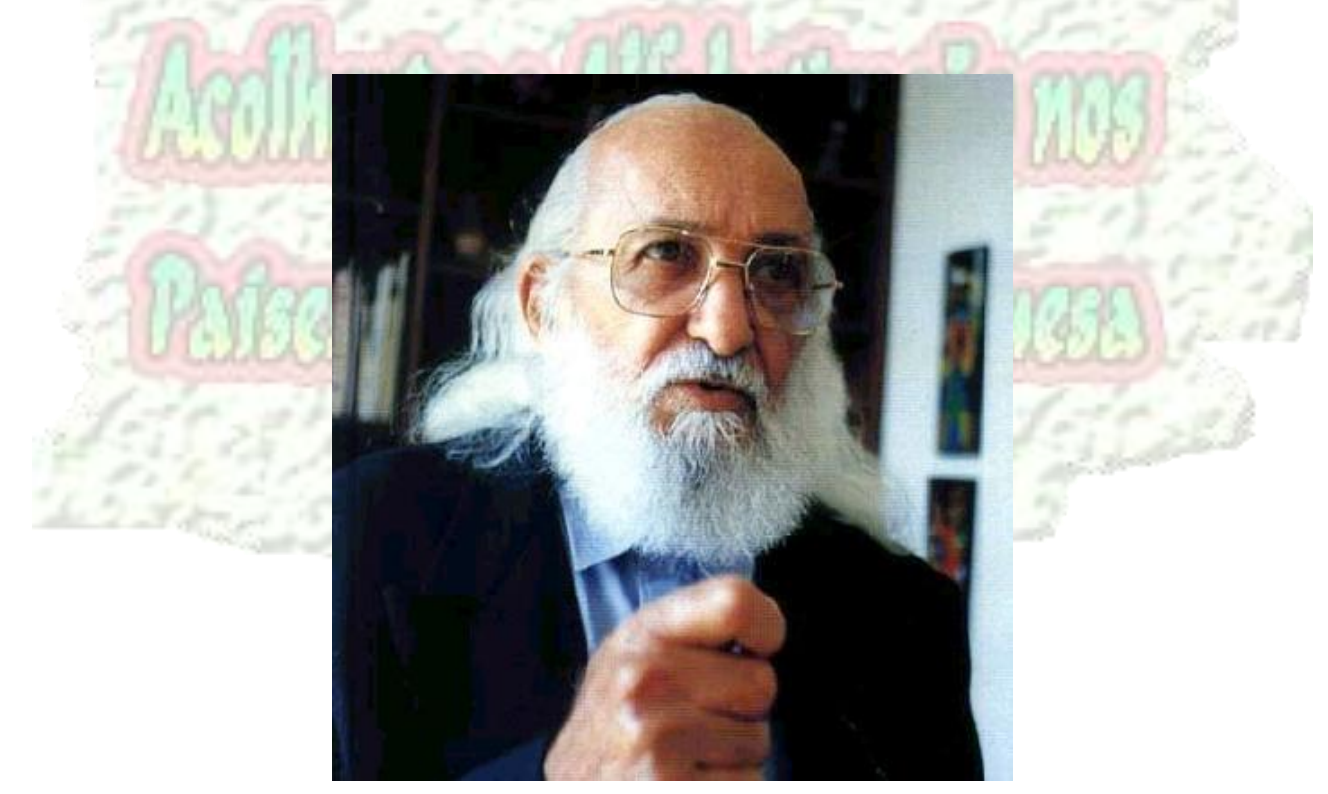

Figura 1: Paulo Freire, educador brasileiro.

Aos 20 anos, Paulo Freire já havia iniciado seus estudos nas áreas de linguística e filosofia da linguagem. Entrou para a faculdade de Direito e, ao mesmo tempo, passou a lecionar Língua Portuguesa em escolas. Aos 23 anos, antes de se formar, casou-se com a professora primária Elza Maia Costa Oliveira, com a qual teve cinco filhos. Anos 
depois, iniciou seus trabalhos com a alfabetização, criando um método próprio para a melhor aprendizagem na vida adulta. Sobre isso, Freire relata:

Lembro-me de minha primeira noite após trabalhar na alfabetização de adultos no Recife. Quando cheguei a casa, Elza me perguntou: "Como é que foi?". E eu lhe disse: "Elza, creio que com o que vi e experimentei hoje, dentro de dois ou três anos muita gente estará me perguntando: 'O que é isso, Paulo?’. Mas é bem possível que eu seja preso. E creio que ser preso é o mais provável." De fato, não três, mas quatro anos depois, fui preso. (FREIRE; MACEDO, 1990, p.115).

Um grande acontecimento marcou a vida de Freire: em 1963, ele alfabetizou 300 adultos em 45 dias, usando um processo próprio para isso. O método Paulo Freire de alfabetização funcionava da seguinte manèira: uma palavra, que devia estar ligada ao contexto do aluno (ou seja, ser conhecida pelo mesmo por representar algo de sua realidade), era apresentada (tomemos a palavra "MESA" como exemplo). Em seguida, separavam-se as sílabas da palavra (ME-SA) e apresentava-se aos alunos a "família fonêmica" de cada sílaba da palavra estudada (ME: ma-me-mi-momu/ SA: sa-se-si-so-su). Por último, apresentavam-se as vogais ao educandó (A-E-I-O-U). Assim, quando o aluno fosse capaz de formar palavras combinando sílabas das mais diversas "famílias fonêmicas", ele estaria alfabetizado. O processo posterior ao da alfabetização, aquele que a tornaria eficaz, é o desenvolvimento das habilidades de leitura e escrita.

No ano seguinte, devido ao golpe militar, Freire teve seus trabalhos interrompidos. Sua prática foi considerada uma ameaça ao novo regime que se instaurava no país: a ditadura militar. Depois de ser preso duas vezes e passar cerca de 75 dias na cadeia, Freire exilou-se no Chile, permanecendo lá por cinco anos. Nos onze anos seguintes em que permaneceu exilado, Freire viajou por alguns países da África para mostrar o quanto sua proposta educativa é aplicável aos países do terceiro mundo. Nos Estados Unidos, foi professor na Universidade de Harvard. Passou também pela Suíça, Peru e Nicarágua. Só retornou ao Brasil depois da Lei 
da Anistia, que concedeu o direito a todos os exilados políticos de voltar ao país em 1979.

Em 1986, morre Elza, vítima de problemas cardíacos. A perda da esposa o abalou profundamente, sendo este um período muito difícil para ele. Anos depois, Paulo decidiu reconstruir sua vida, dando uma nova chance ao amor. Assim, casou-se com Ana Maria Araújo, sua ex-aluna e orientanda de mestrado.

Freire foi Secretário de Educação do município de São Paulo durante o governo da prefeita Luiza Erundina, e trabalhou em projetos culturais desenvolvidos na África e na América Latina até o ano de sua morte (1997). Antes de completar 76 anos, vítima de infarto, o grande educador Paulo Freire nos deixou. Todos os ensinamentos dele serviram para revolucionar o método educacional. Depois de Freire, a educação básica no Brasil e em muitos outros países nunca mais foi a mesma.

\section{Ler o mundo antes das palavras}

Paulo Freire possui uma concepção de leitura que é única e original. Ele considera que para "ler a palavra" é preciso primeiro "lèr o mundo”. Explicitaremos mais detalhadamente essa concepção.

-A ideia freireana nos mostra uma maneira simples, porém muito significativa da aprendizagem da leitura. O início do processo de alfabetização, a leitura em si, deve estar amplamente envolvido com a história e a experiência individual do educando. É preciso que o aluno aprenda baseando-se no ambiente em que está inserido, nas suas vivências e na cultura que o cerca.

Esta apreensão do contexto do aluno é o que Freire denominou "leitura do mundo". A "leitura do mundo" deve ser feita antes que o educando aprenda a "ler a palavra", ou seja, antes que ele adquira um amplo 
vocabulário, conheça as normas gramaticais e consiga dominar a escrita e todos os demais aspectos da língua nativa.

Sendo assim, seria impossível separar completamente a "leitura de mundo" da "leitura da palavra". Em suas próprias palavras, Freire relata:

Ler a palavra e aprender como escrever a palavra, de modo que alguém possa lê-la depois, são precedidos do aprender como "escrever" o mundo, isto é, ter a experiência de mudar o mundo e de estar em contato com o mundo (FREIRE; MACEDO, 1990, p.31).

A leitura só alcançará seu real sentido se estiver ligada à realidade do leitor. Somente após a primeira leitura (a leitura do mundo) o indivíduo estará apto a desenvolver a leitura da palavra. Esta, por sua vez, servirá como instrumento para a contextualização da realidade que nos envolve, e será através da escrita que poderemos levar nossos valores, saberes e anseios para outros povos, pessoas e grupos, cuja cultura é diferente da nossa.

\section{Leitura e conscientização}

Ao desenvolver uma pedagogia progressista e libertadora, que visava proporcionar ao indivíduo um autoconhecimento, o mestre Paulo Freire nos ensinou que existe uma grande relação entre leitura e conscientização. Segundo ele, a consciência é:

[...] gerada na prática social de que se participa. Mas tem, também, uma dimensão individual. Minha compreensão do mundo, meus sonhos sobre o mundo, meu julgamento a respeito do mundo, tendo, tudo isso, algo de mim mesmo, de minha individualidade, tem que ver diretamente com a prática social de que tomo parte e com a posição que nela ocupo. Preciso de tudo isso para começar a perceber como estou sendo. Não me compreendo se trato de me entender à luz apenas do que penso ser individualmente ou se, por outro lado, me reduzo totalmente ao social (FREIRE; MACEDO, 1990, p.29). 
Relacionando a leitura e o processo de alfabetização com a consciência, Freire desperta em homens e mulheres o pensamento crítico e a reflexão sobre a singularidade humana e sobre o meio ao qual o indivíduo está inserido. Ao se conhecer e se perceber como construtor de sua própria vida, a pessoa desenvolve um compromisso com a realidade.

É certo que a consciência por si mesma não é capaz de mudar a realidade social, mas aquele que passar por um processo educativo que possibilite a reflexão estará apto a questionar, criticar e posteriormente melhorar as condições de sua existência. O professor que instigar nos alunos esse sentimento de desenvolver a criticidade fará com que eles assumam e compreendam de maneira responsável o real sentido de suas vidas. Além disso, estes poderão reconhecer o quanto é importante ler e estar alfabetizado para obter crescimento profissional, e acima de tudo, crescimento pessoal, já que só a vivência rica que a leitura nos propórciona é capaz de transformar nosso intelecto.

A consciência foi abordada por Freire como sendo de suma importância para a educação. Por isso, para facilitar o entendimento desté conceito essencial da teoria freireana, ele a dividiu em níveis, que se alteram no decorrer da vida modificando a visão de mundo que o sujeito apresenta.

Nos primeiros níveis, que são os estados de "consciência ingênua", "consciência transitivo-ingênua" e "consciência mágica" (esta presente nos dois níveis anteriormente apresentados), o homem não consegue transcender àquilo que lhe é apresentado, ele ainda não é capaz de enxergar-se além da realidade que já foi objetivada. Ele não é capaz ainda de criticar conscientemente, e muito do que se apresentará ao indivíduo será visto por ele como superstição, ou mera ocasionalidade.

O último nível, que é sem dúvida o mais importante, é a “consciência crítica". Quando o homem atinge esse nível, ele já é capaz de pensar por si mesmo de maneira analítica e reflexiva. Propõe-se a indagar a respeito daquilo que lhe é imposto e daquilo que existe como realidade. 
Criticando, o homem é capaz de rever seus conceitos e paradigmas, tornando-se um ser agente dentro da sociedade.

A educação progressista e o hábito da leitura são os caminhos para que o aluno atinja a "consciência crítica". É através da leitura que o homem descobre os destinos do saber e torna-se idôneo para aprender, criticar e questionar acerca do meio em que vive. Como sujeito ativo e consciente ele age e transforma a sociedade, além de ser dono e construtor de seu próprio destino.

Conscientização, então, é a capacidade humana de ver-se hábil para não só apreender a realidade, mas ultrapassá-la. O homem consciente valoriza sua integridade e dignidade, e vê-se propício a fazer a diferença na construção cultural, social e educacional da sociedade a qual pertence.

\section{Paulo Freire e os caminhos da educação}

A experiência individual de cada um serve como base para a objetivação de valores e para a construção de nossa própria moral. Esse conjunto de valores morais é o que nos guiará em nossas atitudes nó desenrolar de nosso trajeto vital. Ao analisarmos a obra de Paulo Freire, fica claro que suas vivências foram de suma importância para a construção de toda a sua metodelogia educacional, da qual nós brasileiros nos orgulhamos.

Como já foi mencionado anteriormente, Freire teve uma infância árdua no interior pernambucano. Seu primeiro contato com o mundo da leitura e da escrita foi possibilitado por seus pais, especialmente por sua mãe, que o alfabetizou antes mesmo de sua primeira professora, Eunice Vasconcelos. Com orgulho, relembra-se:

Mas, é importante dizer, a "leitura" do meu mundo, que me foi sempre fundamental, não fez de mim um menino antecipado em homem, um racionalista de calças curtas. A curiosidade do menino não iria distorcer-se pelo simples fato de ser exercida, no que fui mais ajudado do que desajudado por meus pais. $\mathrm{E}$ foi com eles, precisamente, em certo momento dessa rica experiência de compreensão do meu mundo imediato, sem que 
tal compreensão tivesse significado malquerenças ao que ele tinha de encantadoramente misterioso, que eu comecei a ser introduzido na leitura da palavra.

A decifração da palavra fluía naturalmente da "leitura" do mundo particular. Não era algo que se estivesse dando superpostamente a ele. Fui alfabetizado no chão do quintal de minha casa, à sombra das mangueiras, com palavras do meu mundo e não do mundo maior dos meus pais. O chão foi o meu quadro-negro; gravetos, o meu giz (FREIRE, 2005, p.15).

$\mathrm{Na}$ juventude, teve a oportunidade de ensinar língua portuguesa em escolas particulares, que exprimiam uma realidade diferente daquela vivida por ele. Em suas palavras:

\begin{abstract}
Algum tempo depois, como professor também de português, nos meus vinte anos, vivi intensamente a importância elo de ler e de escrever, no fundo indicotomizáveis, com os alunós das primeiras séries do então chamado curso ginasial. A regếncia verbal, a sintaxe de concordância, o problema da crase, o sinclitismo pronominal, nada disso era reduzido por mim a tabletes de conhecimentos que devessem ser engolidos pelos estudantes. Tudo isso, pelo contrário, era proposto à curiosidade dos alunos de maneira dinâmica e viva, no corpo mesmo de textos, ora de autores que estudávamos, ora deles próprios, como objetos a serem desvelados e não como aligo parado, cujo perfil eu descrevesse." (FREIRE, 2005, p.15-16).
\end{abstract}

Mesmo assim, essa experiência foi crucial para lhe despertar $\oint$ gosto pela educação e pelos estudos da linguística. Foi nessa mesma época que se casou com a professora Elza, que em muito o motivou a aprofundarse nos caminhos da educação.

Os estudos de Freire sobre a sociedade e as novas correntes filosóficas que se espalhavam pelo mundo, principalmente a Fenomenologia, serviram de base para as reflexões pedagógicas que ele desenvolveria posteriormente. Paulo Freire possibilitou uma revolução na Pedagogia, tornando-a crítica, aplicável e altamente inovadora.

O grande interesse de Freire em levar a leitura e a escrita àqueles que não tiveram a oportunidade de estudar na infância surgiu do amplo envolvimento que ele tinha com os operários, camponeses e pescadores de Jaboatão (PE), cidade na qual passou grande parte de sua 
infância e juventude. A prática da leitura, a alfabetização em si, seria o único caminho para diminuir o enorme abismo que separa as classes sociais.

Outra experiência marcante na vida desse magnânimo pedagogo foi a prisão e o posterior exílio a que se submeteu no período ditatorial. Ele só foi preso porque suas ideias não favoreciam a classe dominante e, portanto, eram consideradas uma ameaça ao regime, já que despertariam o conhecimento e a consciência crítica dos indivíduos.

\section{O que aprendi no exílio é o que recomendaria a todos os leitores deste livro: esteja todo dia aberto para o mundo, esteja pronto para pensar; esteja todo dia pronto a não aceitar o que se diz, simplesmente por ser dito; esteja predisposto a reler o que foi lido; dia após dia, investigue, questione é duvide (FREIRE; MACEDO, 1990, p.116).}

Foi durante o exílio que Paulo Freire pode mostrar ao mundo sua nova proposta para a reformulação dos parâmetros educacionaīs. Nas diversas viagens que realizou, teve a oportunidade de conhecer os mais diferentes povos e culturas. Em sua passagem pelos Estados Unidos, pôde perceber que, mesmo em um país de primeiro mundo, ainda há muito que melhorar na educação, especialmente no que concerne ao ensino público. Outra realidade bem distinta foi a que encontrou no continente africano, no qual visitou muitos países. Lá Freire percebeu o quanto súa teoria seria aplicável, e viu seu trabalho ser merecidamente reconhecido, especialmente em São Tomé e Príncipe e Guiné-Bissau.

\section{Adaptação do método freireano: Projeto "Minha escola... Minha vida..."}

Após o estudo da concepção de leitura e alfabetização criada por Paulo Freire, viu-se a possibilidade de adaptá-la para o ensino infantil. A proposta é basicamente a mesma: proporcionar aos alunos uma leitura de "mundo" antes da leitura das "palavras". Assim como funcionou o método com adultos, com crianças não poderia ser diferente: o projeto "Minha 
escola... Minha vida..." foi de suma importância para a alfabetização das crianças que tiveram a oportunidade de participar. Relataremos como funcionou o projeto na Escola Municipal "Dr. Martim Paulucci” localizada no município de Barbacena (MG), em uma comunidade periférica e essencialmente carente, cuja infraestrutura é precária, faltando em alguns pontos condições básicas de saneamento e higiene, além de elevado número de pessoas com baixa escolaridade.

No ano de 2009, as duas turmas do segundo ano da Escola Municipal "Dr. Martim Paulucci” participaram do projeto. O desejo era possibilitar aos alunos uma aprendizagem eficiente através do conhecimento de sua própria história. Envolver a família no processo de aprendizagem valoriza não só o aluno bem como sua identidade diante da comunidade na qual ele está inserido, proporcionando uma socialização prazerosa.

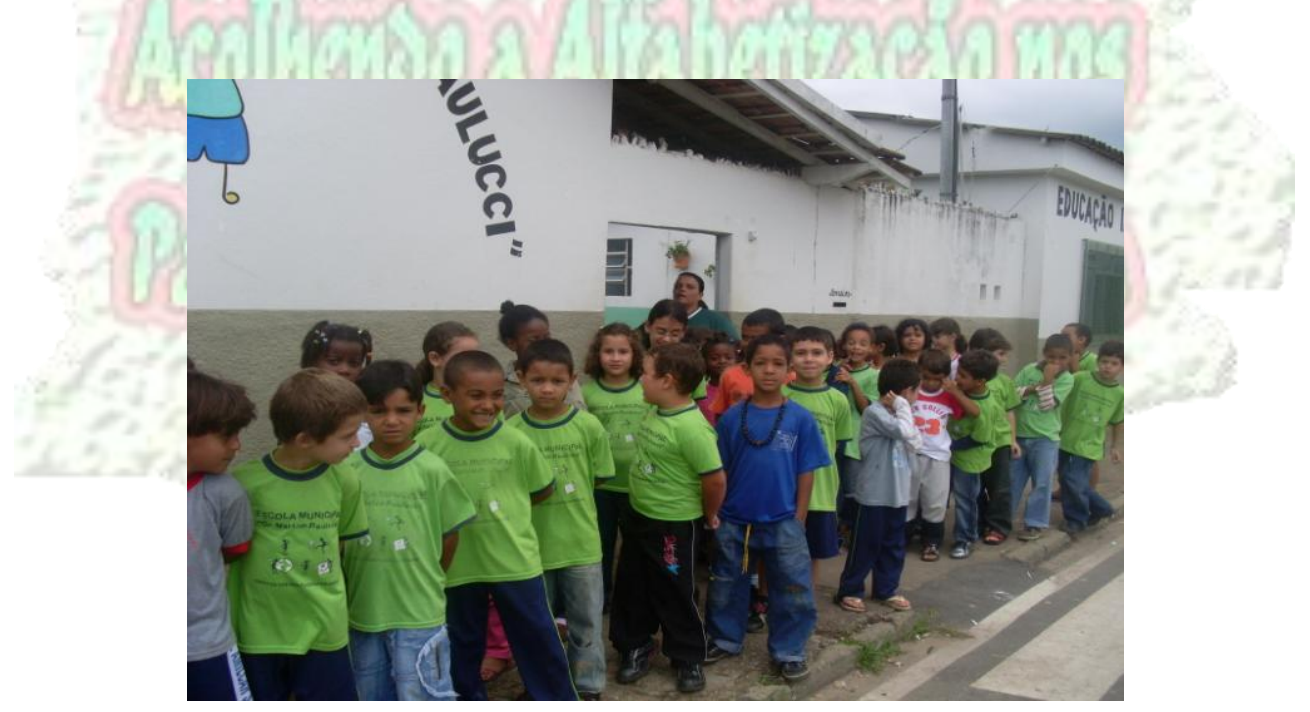

Figura 2: Alunos saindo da escola para mais uma visita

Uma vez por semana um aluno recebe os colegas em sua casa. Durante essa visita ele tem a oportunidade de mostrar onde vive, o que gosta de fazer, qual a profissão de seus pais, porque escolheram aquela comunidade para morar, há quanto tempo moram lá, dentre outras coisas. O 
aluno visitado também mostra aos colegas seu brinquedo favorito, seu animal de estimação e seu quarto.

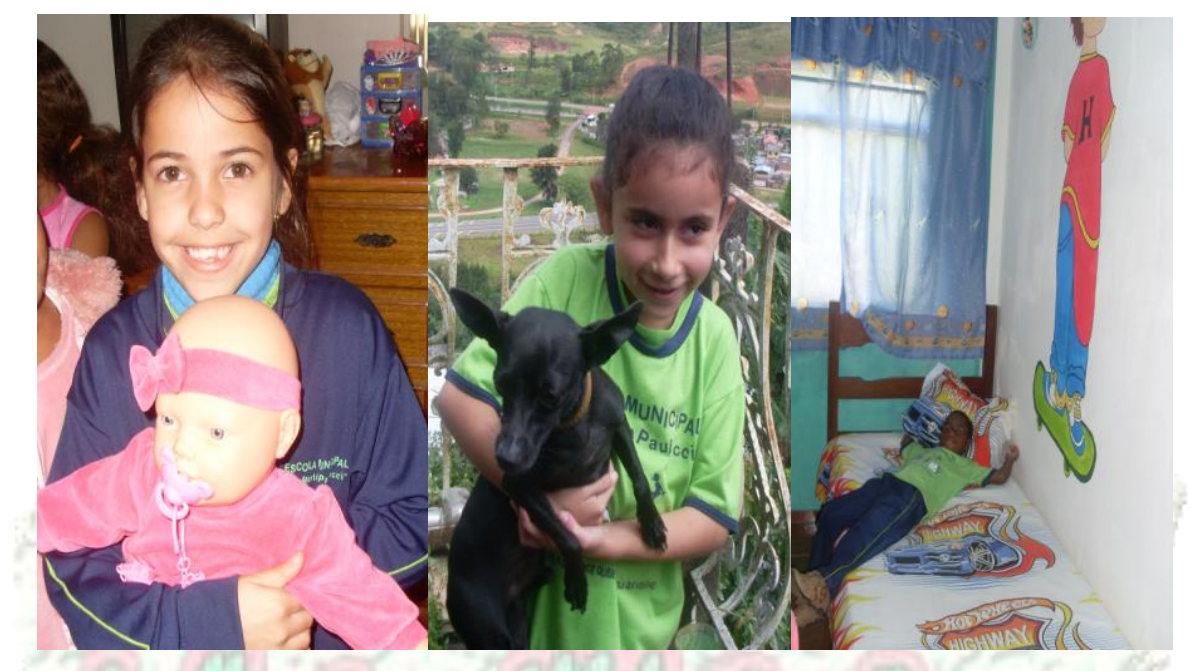

Figura 3: Brinquedo preferido, animal de estimação e o quarto de algumas das Érianças visitadas.

Depois disso, os pais ou responsáveis pela criança são convidados a ler um clássico literário para turma. Além disso, eles também relatam uma pequena história que tenha marcado sua vida, ou a vida de seu fitho, conforme sua preferência.

Já em sala de aula, as crianças relembram tudo o que foi visto: aprendem a escrever o nome da mãe/pai do colega visitado, do animal de estimação, do brinquedo preferido e da rua onde ele mora. Todo esse processo é trabalhado dentro dos conformes do método freireano. Exemplifiquemos:

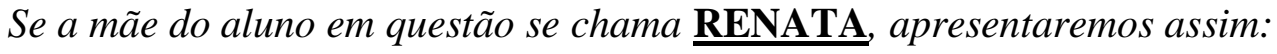

\section{RENATA}

Separamos as sílabas: $\mathbf{R E}-\boldsymbol{N A}-\boldsymbol{T A}$

Apresentamos a família fonêmica de cada sílaba: 
$R E: R A-R E-R I-R O-R U$

$N A: N A-N E-N I-N O-N U$

TA: $T A-T E-T I-T O-T U$

Por último, relembramos as vogais: $\boldsymbol{A}-\boldsymbol{E}-\boldsymbol{I}-\boldsymbol{O}-\boldsymbol{U}$

Além desse processo inicial, são desenvolvidas outras atividades, tais como: pintura, reprodução oral e escrita do que foi visto, produção de textos coletivos, dramatizações, confecção de fantoches, recontagem e remontagem das histórias ouvidas.

A parceria entre escola, comunidade e família oferece condições para que a criança adquira o hábito da leitura, autonomia crítica e compreensã da realidade que a cerca.

Acredita-se que a aplicação do projeto contribuiu de forma efetiva e proveitosa para o processo de alfabetização dos alunos. Em sala de aula, observou-se um aumento da frequência às aulas, da disciplina e dó prazer em realizar as lições.

As atividades propostas foram contextualizadas com a comunidade e a realidade das crianças, contribuindo para o desenvolvimento das habilidades de criticidade e aplicação en seu meio. $\mathrm{O}$ objetivo do letramento é exatamente esse: tornar o aluno capaz de apropriarse e fazer o uso social da leitura e da escrita para suas necessidades cotidianas. Referimo-nos aqui a crianças de 7 ou 8 anos de idade que já estão aptas a usar os benefícios que a aprendizagem lúdica traz em seu dia a dia.

O processo avaliativo é realizado gradativa e continuamente, partindo de um diagnóstico inicial. Seguindo as sugestões do CEALE (Centro de Alfabetização e Escrita da Faculdade de Educação da UFMG) foi feita uma avaliação diagnóstica das capacidades desenvolvidas no aluno antes do início do projeto. Posteriormente, essa avaliação ocorria a cada 
sessenta dias, para que pudesse ser acompanhado o nível de desenvolvimento alcançado pelos alunos. As atividades variaram conforme a evolução ocorrida durante a execução do projeto, sendo considerados, principalmente, a participação individual e coletiva e o nível de envolvimento com o mesmo.

O alto índice de aprovação e alfabetização completa alcançado por esses alunos (superior a 90\%) prova o quanto essa experiência foi válida e aplicável. Foram desenvolvidas não só as competências de leitura e escrita, mas também a interpretação oral, a sociabilidade, a comunicação, a organização, a liberdade de expressão e a amizade entre os alunos, habilidades essenciais para toda a vida do eduicando.

Diante desses resultados, espera-se que o projeto seja amplíado, para que mais alunos possam participar. Aplicá-lo novamente é um importante passo para que se possa aperfeiçoá-lo, criando novas atividades e propostas que incluam a interdisciplinaridade e uma maior interação entre a família e a escola.

\section{Considerações finais}

Paulo Freire, com toda a sua sabedoria, nos ensinou o real sentido dä teitura, e o valor que ela tem no decorrer de nossa existência, desde o processo de alfabetização. Suas vivências e experiências pessoais possibilitaram seu crescimento e interesse pela educação, que ainda tem muito que evoluir.

Quando desenvolve um método próprio para a alfabetização, Freire reconhece a imensa importância que esta tem para a formação do indivíduo. Ao falar sobre a importância da "leitura do mundo", ele nos abre os caminhos para pensar a nossa realidade e a partir dela construir nosso próprio saber. Ler o mundo deve ser um exercício praticado durante toda a nossa vida, pois só aquele que conhece sua própria existência é capaz de 
aprender o real significado da "leitura da palavra". "Ler a palavra" associada à "leitura do mundo" será, pois, uma atividade prazerosa, rica e produtiva.

O projeto "Minha escola... Minha vida..." foi uma maneira de desafiar a pedagogia freireana, provando o quanto inovações nesse método de alfabetização são válidas. Alfabetizar crianças baseando-se na proposta de Freire é uma experiência que trouxe bons resultados, tanto para os alunos que participaram do projeto quanto para a comunidade envolvida no processo.

Freire renovou a Pedagogia ao crer na educação conscientizadora. Aquele indivíduo que for então capaz de "ler o mundф" e "ler a palavra" conscientemente estará apto a construir seu próprio espaço de maneira válida e digna. A leitura auxilia na formação da consciência crítica por desenvolver a reflexão, exercitar o pensamento e induzir o sujeito a transcender à sua própria realidade. A conscientização humaniza e dá sentido à existência, garantindo a liberdade de expressão e a responsabilidade por saber-se único e construtor de uma vida que também é única.

Paulo Freire soube em vida nos ensinar a verdadeira essêneia da educação. Ele atiçou em nós, alunos e mestres, a vontade de lutar por um ensino mais humano, que desperte naqueles que estão aprendendo o desejo de conhecer e criar um mundo que conceda dignidade a todos.

\section{Referências Bibliográficas}

BRANDÃO, C. R.. O que é o método Paulo Freire. São Paulo: Brasiliense, 1981.

FREIRE, P.. A importância do ato de ler: em três artigos que se completam. São Paulo: Cortez, 2005. 
Pedagogia da autonomia: saberes necessários à prática educativa. São Paulo: Paz e Terra, 1996.

; MACEDO, Donaldo. Alfabetização: leitura do mundo leitura da palavra. Rio de Janeiro: Paz e Terra, 1990.

GADOTTI, M. (org.). Paulo Freire: uma biobibliografia. São Paulo: Cortez, 1996.

SIMONSEN, M.. Elaboração e análise de projetos. São Paulo: Sugestões Literárias, 1974.

\section{Autores:}

Eliane de Paula Rocha

Professora alfabetizadora hem Barbacena - Minas Gerais.

Contato: elianepaularocha@yahoo.com.br

Doutor Ignácio César de Bulhões

Professor da UFSJ

Contato: ic.bulhoes@gmail.com

Texto recebido em fevereiro de 2011.

Texto aprovado para publicação em fevereiro de 2012.

\section{Como citar este texto:}

ROCHA, E. de P.; BULHÕES, I. C. de. Adaptação do método freireano para a alfabetização infantil. Revista Acolhendo a alfabetização nos países de língua portuguesa, Brasil, São Paulo, volume 1, nº 12, p. $50-65$, Mar. 2012. Disponível em: <http://www.acoalfaplp.net>. 